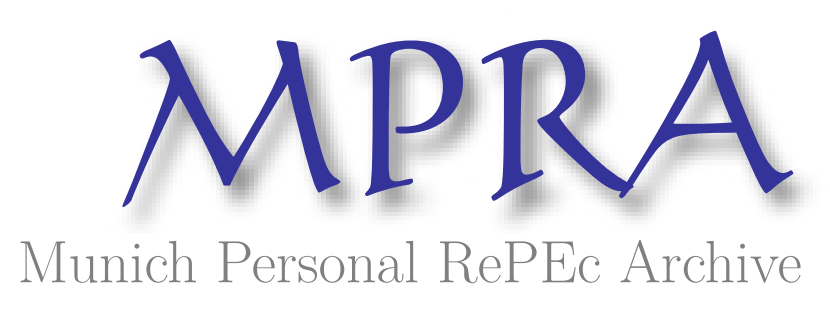

\title{
Critique of IS-LM: fiscal deficits, loanable funds, Keynesian Cross and IS-LM
}

Kim, Minseong

21 September 2014

Online at https://mpra.ub.uni-muenchen.de/59422/

MPRA Paper No. 59422, posted 22 Oct 2014 04:44 UTC 


\title{
Critique of IS-LM: fiscal deficits, loanable funds, Keynesian Cross and IS-LM
}

\author{
Minseong Kim
}

\begin{abstract}
This paper intends to discuss some problematic aspects that IS-LM have when dealing with fiscal deficits, especially when considering loanable funds model. Many others have focused on its assumptions for criticism of IS-LM, but I will mainly focus on its fundamental modelling nature. To say more specifically, I will argue that ordinary ISLM analysis is in contradictory nature to simultaneous equilibrium system, and therefore loanable funds. I will stick completely with IS-LM language for this paper. Therefore, any opinion expressed about economy in this paper stems from either IS-LM or correction of IS-LM analysis, not from my academic and personal stance toward economy.
\end{abstract}

\section{Short-run and long-run}

It seems that there are two variants related to loanable funds model. First is that while money market determines short-run interest rate(s), loanable funds market determines long-run interest rate(s). Second is that money market determines nominal interest rate, while loanable fund market determines real interest rate, though sometimes money market is also seen as determine real interest rate together with loanable fund market. In this paper, I will discuss mainly the second interpretation.

\section{The General Theory and the birth of IS-LM}

In Chapter 14 of The General Theory of Employment[1], Interest and Money by John Maynard Keynes, it is argued that loanable funds model cannot only determine the rate of interest, because saving curve is dependent on total income economic agents receive. So suppose that government spends to stimulate economy. Then loanable funds model would say that the rate of interest increases due to fiscal deficit in short-run. However, this is only because total income $Y$ is considered as constant, which is not going to be true.

It is in this spirit that IS-LM was born. It is not really important here whether Keynes had a real influence on the originators, like Harrod and Hicks, of IS-LM, so I will not discuss this matter. 
While it is true that IS-LM is now considered by many, including the author, to be an obsolete model, it nevertheless appears in many policy debates and textbooks. Therefore, the author believes that it is worth considering the nature of IS-LM. Economics always strives to find a simple and elegant explanation that may work given that certain conditions are met.

\section{3. loanable funds, IS-LM and fiscal deficits I}

In this section, fiscal deficits will be mainly discussed.

In IS-LM, IS and LM curve map each different baseline rate of interest $r$ with each different output $Y$. When government deficit-spends, IS curve moves to right, which generates higher $r$ and $Y$, except when economy faces flat LM curve - often called liquidity trap, though terminology would not be so correct. In such trap scenario, government deficit-spending will not induce higher $r$, and government in time of recession and such trap can exploit this to reach full employment. The definition of full employment is different from a person to person - but I will ignore this issue, as this is not the intended discussion area of this paper.

IS curve is often derived using Keynesian cross or using loanable funds model. In the former, increased planned investment due to lower interest rate shifts planned expenditure curve upward, and as $Y=P E$ in Keynesian cross equilibrium, increased output results. In the latter, desire to save is greater than desire to invest when $Y$ increases, generating IS-LM. While Keynes does not seem to express rejection or endorsement of this type of IS-LM, a such interpretation is indeed in the diagram of Chapter 14. It is arguable (and questionable, in several countries and individual cases) whether desire to save becomes greater than desire to invest when $Y$ increases, but the paper will simply assume that this is true.

Let me for now resurrect the discussion of flat LM curve. It is said that when an equilibrium faces flat LM curve, ( $r$ in vertical-axis and $Y$ is horizontalaxis) it is possible to stimulate an economy by deficit stimulus spending without increasing $r$. Is this sustainable in normal loanable funds model? For this, it might be much preferable just to refer to introductory/intermediate macroeconomics textbooks available. I will choose N. Gregory Mankiw's Principles of Macroeconomics 6th edition[2] and Macroeconomics 7th edition[3] as reference.

In page 274 of the 9 th edition of Principles of Macroeconomics, N. Gregory Mankiw states that when deficit spending is carried out, national savings decrease - meaning saving curve in loanable funds moves left. The conclusion is that $r$ in short-run increases and quantity of loanable funds $Q$ decreases. 
Additionally, it is stated: "Because investment is important for long-run economic growth, government budget deficits reduce the economy's growth rate."

To be a bit off of the paper's main arguments, the conclusion reached by Mankiw seems to be highly misleading. It is not clear what Mankiw actually intended. First of all, if Mankiw intended that even after fiscal spending is carried out in one single-time saving curve will remain shifted to left because national savings decreased due to $G-T(G$ : government spending, $T$ : government revenues, including taxes) decreasing, Mankiw is definitely wrong. While it is true that $T-G$ becomes negative when government deficit-spends, government needs money to carry out deficit spending. Let us for now say that the pool of money available, $M_{p o}$ is fixed. Then government will borrow from private agents. Because government took away money of private agents with a promise to pay them back, available pool of money does decrease. However, after government does spend the money it borrowed, the pool of money $M_{p o}$ becomes intact.

Therefore, in order for the Mankiw's conclusion in Principles of Macroeconomics to hold, 1 . the shape of investment and saving curve in loanable funds model would be something unconventional or/and 2. Mankiw is arguing that because fiscal spending takes time to be carried out, national savings remain decreased, driving $r$ high for some times or/and 3. liquidity preference takes more roles, more specifically cash-hoarding or/and 4 . some of savings induced by government spending become not available for loanable funds due to financial(including things involving different interest rates, et cetera) and investment plan issues that would necessitate a need to make IS-LM more complex.

While Point 1 and Point 2 in the preceding paragraph will be clear to most readers, Point 3 may not be clear, so I explain. Let us assume that government spends $G$ by borrowing from private agents entirely. Let us say one individual/firm $a_{1}$ receives all $G$. While this is not a realistic simplification, the approach can surely be generalized. Then $a_{1}$ will consume parts of $G$, invest parts of $G$ and save parts of $G$. Then $G=c_{1}+i_{1}+s_{1}$. We notice that from the saving of $G$, now saving is $s_{1}$. But is wrong to conclude that saving $G$ has become $s_{1}$. For $c_{1}$ and $i_{1}$ will also be given to others - and in the end, saving $G$ will be retained. However, if $a_{1}$ has strong preference toward holding cash (liquid asset, paying zero interest) instead of interest-paying asset that is considered almost riskless, though is not completely riskless (but it is also wrong to say cash is a completely riskless asset all the time), then it may not be true that all of $G$ may become available as loanable funds. In such case, amount of national savings remain repressed, and $r$ remains high, until it returns to the natural baseline rate of interest $r^{*}$. 
Point 3 merits its own important note - that in certain situations, loanable funds model does require specification of liquidity preference, specifically cash-hoarding nature. If one lives in a world where cash-hoarding is irrelevant, then unless more complicated financial structures are elaborated in IS-LM, Point 3 is almost not possible. In a certain sense, Point 3 is a restatement of the Keynes's argument against pure loanable funds model, but from a different perspective.

It seems that Mankiw does notice Point 2, as seen in page 297 of Macroeconomics, discussing Obama fiscal stimulus plan, but it is not clear if he has this in mind in loanable funds context. If he does, it is unfortunate that he did not state this clearly. But delays of investments carried out by private sector are in reality, and some may suggest that only considering government as a delay source is a bit unfair.

Regardless, let us consider the case where because people demand liquid cash, the full saving $G$ does not come back completely - that is, let us neglect Point 1 and 2 and just assume Point 3. Then, considering investment curve as referring to private investment solely, saving curve is still left to the saving curve before borrowings for deficit-spending occurred. Assuming no central bank operation, $r$ will remain higher and quantity of loanable funds will remain lower.

Again, if there is no such thing as cash-hoarding liquidity preference, then saving curve returns to normal level and original equilibrium interest rate and quantity of loanable funds returns.

But from the above, we just noted the complaints made by Keynes that this type of saving curve ignores the relationship between savings and income. I will address this part in the following section.

\section{4. loanable funds, IS-LM and fiscal deficits II}

For this section and afterwards, let us assume that there is no cash-hoarding preference in an economy. This means that saving curve just returns to the previous level before deficit spending, with investment curve remaining the same, assuming $Y$ has not changed. This implies that when LM curve is not flat, even in short-run government deficit spending does not increase $r$, therefore inconsistent with the movement of IS curve. When LM curve is flat in equilibrium, then loanable funds and IS-LM can coexist together. These all assuming that $Y$ remains constant.

But the assumption related to $Y$ is exactly what we need to question. What happens to $Y$ in a loanable funds-included model?

One may say due to marginal propensity to consume (MPC), $Y$ needs to 
increase in a multiplier fashion by government deficit spending, as in Old Keynesian logic - New Keynesians think differently, but as we stick with discussion of static models, in which IS-LM is part of, we will mostly discuss Old Keynesian logics, while static New Keynesian models certainly exist, as a sideline model. After all, this paper is not about questionable assumptions, but how consisting theories fit well together.

However, this is a wrong characterization of how equilibrium model works. Let us think of an economy with homogeneous agents - so everyone has same MPC. Realistically, these agents do not operate at a single time as in a static simultaneous equilibrium model. In an equilibrium model and reality, these agents consume, invest and save. Let us focus on saving. Saving generates investment, according to neoclassical theory, as can be inferred from the models, in loanable funds fashion. Then this investment becomes someone else's income, and so on. What a simultaneous equilibrium model like a loanable funds-included model then does is incorporating all these events that have occurred in several time periods into a single time period that can be solved in equilibrium manners.

This implies that there is no reason to think of government interventions as something that stands out of private decisions, if they are considered occurring in the same time period as private decisions are in. Therefore, if everyone is homogeneous, output $Y$ is not affected by deficit spending.

Relaxing our assumption that all agents be homogeneous, deficit spending can affect $Y$ positively in short-run. If government borrows from the people that have less MPC and spends money toward people that have more MPC, then it may be possible that $Y$ is affected positively. (You can replace MPC with productivity also)

But this argument is not directly related to IS-LM or loanable funds model. Indeed what is really required is non-homogeneity of economic agents, not these models. IS-LM together with loanable funds model remain inapplicable.

The other possibility is that the roles of inventories may be greater than what IS-LM and loanable funds model express. Indeed, in NIPA accounting, investment is defined as containing inventories. However, this again has not much to do IS-LM, but may have more use in Keynesian cross. This does not change the fact that IS-LM will still not be consistent with loanable funds model.

In this stage, I am somehow afraid that I may have said things that some people already have known - though some people miss these apparently. But this seems to be important and often missed - while there are some very questionable and likely wrong arguments made by some New Classical writers, I believe that the things I mentioned above are also in some people's 
minds, although they have not expressed those in a way I did here. [4][5] In a certain sense, this is the savings version of Sumner critique[6] - all government does in homogeneous economy is just replacing someone's role of transferring money to others. (In Sumner critique, if government increases aggregate demand $(\mathrm{AD})$, thereby violating central bank's target of $\mathrm{AD}$, then central bank just pushes back $\mathrm{AD}$ so that the target can be met in AS-AD model.)

\section{Saving curve moving left, or investment curve moving right? I}

In the previous section, investment side in loanable funds is defined as referring to private investment. What if investment side is defined as referring to total investment, both private and government? If one follows the standard description of only investment curve moving to right after government deficit spending, would not loanable funds/IS-LM result in more output and higher $r$ ? After all, this approach does not seem to suffer from the flaws we saw in the Mankiw's textbook, as we no longer have to move savings curve. For simplification, let us think of an economy where all agents are homogeneous. Note that it is absurd to think of investment curve as being invariant to $Y$. If $I$ is invariant to $Y$, then as $Y$ increases, saving $S$ would shift right until one reaches lower bound real interest rate. This cannot be true, unless someone has a different vision of an economy. But this means that what Keynes said as lacking in pure loanable funds model applies applies to investment side. If we do not know what final output $Y$ will be, we cannot talk about what definitive investment curve will be. As said in the previous section, it is wrong to think that government investment obviously boost output - one should not just think that final investment equilibrium curve will be before-deficit-curve plus government deficit spending, because we are talking about simultaneous equilibrium models here.

\section{Another trouble for the combination of loanable funds and IS-LM}

This section is in relation to Point 3 and the previous section. Let us think about an economy with non-homogeneous agents so that $Y$ can be increased by deficit spending. What happens in loanable funds model? If we assume that quantity that is desired to save is proportional to $Y$, then saving curve shifts to right. It is unclear how investment curve will behave - but let us assume that it does shift right. If investment curve's shift is less than saving curve's shift, then we generate IS curve as said above, and loanable funds 
indicate lower $r$ with higher quantity of loanable funds than before deficit spending. As we saw in other sections, it is wrong to think of fiscal deficit as movement of IS curve to right, so the one just elaborated is the right approach. But in equilibrium, we had a certain loanable funds amount. Where do extra loanable funds come from? In the above, it can be seen clearly that government deficit spending does not generate extra total savings. Then it must come from private agents. But people cannot save more than what they can save. They can individually change MPC, but that does not change total savings. Unless other financial structures are provided, or cash-hoarding preference is introduced, there is no way that total loanable funds may change. Therefore, it seems that for IS-LM cash-hoarding is crucial than most people expect. Without cash-hoarding preference, IS-LM does not work, and extra loanable funds due to output increase from government deficit spending are only available because extra cash was left that react to income change. However, even in such case, different reaction functions to output increase, whether for homogeneous agents reacting the same way or for heterogeneous agents, may yield results that are inconsistent with our predictions.

It is also true, of course, that since our IS curve (without cash-hoarding) did not shift, in order for higher output to occur, LM curve needs to move. But since IS-LM is, for most parts, fixed-price analysis, it is beneficial for us not to go too deep with IS-LM for now.

There are, though, three ways to think of a way out without emphasizing cash-hoarding. First is considering saving curve in loanable funds model as indicating mainly cash-hoarding liquidity preference. That is, in lower $r$, people consider cash and interest-bearing savings as almost equivalent, so agents do not provide much supply of loanable funds, but in higher $r$, people come to appreciate interest-bearing savings, so supply gets more provided. Second approach is, basically doing what original neoclassicals did. That is, assume vertical supply curve. Depending on how vertical supply curve is established vertical supply curve may solve the issue underlined above. Third approach is accepting that $Y$ does not increase after deficit spending.

\section{Saving curve moving left, or investment curve moving right?} II

Now with reference to the previous section, we will discuss some of troubling aspects of investment-curve-shifting-right-in-loanable-funds approach to government deficit spending. Let us abbreviate this approach as ICSR approach. As done with some other sections, an economy is assumed to have 
no cash-hoarding behaviour.

ICSR approach says that whenever government deficit spending increases, quantity of loanable funds increases. But as we have seen in the previous section, without extra cash-hoarding - or other relevant reasons for which ISLM cannot be used as a model of economies - there can be no way that extra loanable funds for the increase of quantity of funds exist. While Mankiw's non-ICSR approach allowed at least saving loanable funds and IS-LM approach by taking the Third approach - that government deficit does not increase output, ICSR approach does not allow such rescue.

We may also think in terms of having two markets: one for private loanable funds market and one for government bonds market (though I will not go over details - I will deal only with very simplified concepts for now). When government increases deficits, Each market, in equilibrium, concurrently establishes a new interest rate for the event of government borrowing. How equilibrium is established is that because government deficits dry up, national savings decrease for temporary time and interest rate does increase. However, after government spends that money - national savings in loanable funds market come back, generating a new equilibrium $r$.

This shows that either ICSR approach is misleading, or ICSR approach conflicts with the account of several time periods. That is, ICSR approach may be generating a wrong conclusion because several time periods have been gathered in a wrong way. Either way, ICSR approach is difficult to defend or is misleading, assuming non-ICSR and ICSR approaches, in the end, are the same thing as Mankiw asserts.

\section{Keynesian Cross approach}

As said in first few sections, Keynesian Cross model is often used to derive IS curve. While I have focused on loanable funds interpretation of IS-LM, there may be possibility that Keynesian cross may save ordinary IS-LM fiscal deficit analysis. The verdict that will be reached at the end of this section is that Keynesian cross model is incompatible with how IS curve is designed to be.

There are different interpretations of Keynesian Cross model, but in general they share same qualitative ideas. Following Mankiw's interpretation (page 289 of Mankiw's Macroeconomics), as we have done so far, Keynesian cross model represents intersection of planned expenditure $(P E)$ curve with the actual output/income $(Y)$ line which is the 45-degree line. Let $P E$ be in $y$-axis, and $Y$ be in $x$-axis. $P E=C+I+G$ where $C=C(Y-T)$, meaning that $C$ is function of $Y-T, I=I(Y-T, r)$. While in loanable funds model, 
$I$ often includes $G$ as well, from now one, $I$ will strictly represent private investment, not government spending. In equilibrium, $P E=Y$. Because $I$ is the function of $r$, if $r$ decreases, then $P E$ curve shifts up ( $y$-axis) by $\Delta I_{1}$, and if $r$ increases, then $P E$ shifts down by $\Delta I_{2}$. Mapping the equilibrium points $Y=P E$ that correspond to each $r$ ceteris paribus is what IS curve does.

In ordinary Keynesian-Cross-IS-LM analysis, when government increases deficit spending, $P E$ shifts up by $\Delta G$, amount of government spending increase. Then $Y$ and $P E$ both increase by $\Delta G /(1-M P C)$ by equilibrium/multiplier effects. This shifts IS curve to the right ( $x$-axis) by $\triangle G /(1-M P C$ ) (where $y$-axis is $r, x$-axis is $Y$ ). But LM-side is not modelled, which means that in final equilibrium, $Y$ may not increase by $\Delta G /(1-M P C)$. Interaction with LM changes $r$, which shifts PE curve in Keynesian Cross.

What should be noticed is that IS curve is the set of equilibrium points, and therefore $Y=C+I+G=P E$ necessarily for IS curve. And assuming that IS curve itself does not change then any new intersection of IS-LM curve caused by shifts and movements of LM curve should be attainable. If IS curve changes, then every point in the new IS curve should be attainable with corresponding movements of LM curve.

This suggests us to look at the case where, after $G$ increases shifting IS curve to the right, $Y_{1}$ did not increase because LM curve moved in a corresponding way. This does not mean that $G$ increase caused LM curve to move - rather, we can imagine a central bank changing money supply independently of $G$ increase. But in such case, $r$ increases unless in Hicksian liquidity trap. Due to increase in $r$, investment necessarily changes, because $I=I(r)$ and $Y$ did not change. If complete crowding-out did not occur so that $\Delta I<\Delta G$, then by $Y=C+I+G, C$ necessarily needs to decrease.

Therefore, $C$ 's independent variable cannot purely be $Y$, and in order to ensure consistency of IS-LM, $C=C(r, Y)$. If one works with purely Keynesian Cross model, though, $C=C(r, Y)$ is not needed. $C$ can still be function purely of $Y$.

This is important, because derivation of IS curve from Keynesian Cross is done by assuming that $C=C(Y)$, not $C=C(r, Y)$. To restate things, assuming that $C$ function is linear, $C=a+b Y$ is assumed in Keynesian Cross, rather than $C=a+b Y+c r$. This means that the whole derivation of IS curve is done wrongly, because now one cannot sustain $C=C(Y)$ assumption. To correct the problem, one needs to model consumption behaviour to $r$, possibly under intertemporal setting which is outside of Keynesian cross and for intertemporal setting, IS-LM analysis.

Otherwise, it must be the case that increase in $G$ crowds-out completely 
private investment, that is $\Delta G=-\Delta I$.

While the above consistency check is enough for our purpose, one may go further and think of the reason why Keynesian-Cross-IS-LM analysis in the end does involve loanable funds, except in a special case. In national income accounting and in equilibrium, $C+I+G=C+S+T$. Ignoring taxes for now - that is government does not tax its citizens, we get $Y=C+I+G=C+S$. That is, $I+G=S$, which goes back to loanable funds model if $S=S(Y, r)$. Only when $S=S(I)$ where $S(I): S=I+G$ with $I$ as an independent variable for $S$ would loanable funds model be avoided. If $S=S(I)$, then $S$ does not need to be modelled at all, as $I$ automatically determines $S$.

If one does not adopt $S=S(I)$, then what we get from loanable funds understanding of IS-LM must match with Keynesian Cross understanding of IS-LM. For that reason, I have not and will not discuss Keynesian Cross understanding of IS-LM any further - for $S=S(I)$ would anyway be outside the scope of this paper and for other cases loanable funds understanding is enough for our analysis.

\section{More intuitive discussion of ICSR approach}

Let us now think about how non-ICSR and ICSR reality may, if that is, be different. That is, while we assumed that "the reality" in the analysis above is the same one, here we consider cases where each approach corresponds to a different reality. I hope analysis above gets another dimension with this intuitive discussion. Cash-hoarding is excluded by assumption. In nonICSR world, government borrows from initial government bonds market and private investment gets funded in a separate market. In ICSR world, both government spending and private investment get funded in the same market. Referring from analysis above, when government deficit spending increases by the same amount for both markets, non-ICSR world may experience a very short-term increase in $r$, but $r$ returns back to original level unless $Y$ increases (or even decreases). As one will see, we do not have to make a call on what $Y$ might be for now. In ICSR world, by ordinary IS-LM analysis, $r$ increases with increase in $Y$. Ignoring institutional detail, everything is same for two realities - $G$ increases by the same amount, agents are the same people and so on - except that $r$ is different.

But note that it is actually ICSR world that has higher $r$. This strongly suggests that ICSR world having higher $Y$ than non-ICSR world in the short-run end would really be weird. Higher $r$ usually is associated with lower consumption and lower private investment, but non-ICSR world has 
lower output.

If the short-run end result is that non-ICSR world has greater $Y$ compared to ICSR world, then it will be sensible for agents to switch to non-ICSR world from ICSR world. And we are already in non-ICSR world, making ICSR analysis irrelevant for fiscal analysis. After all, fiscal authority would want to have higher $Y$ as possible.

\section{Extraneous mentions: AD-AS model}

While this paper focuses entirely on IS-LM and loanable funds, it may be worthwhile to mention AD-AS model, because AD-AS, for most of time, is built upon IS-LM. If what is said above is accurate analysis, then it is clear that AD-AS which relies on IS-LM cannot be used.

There were certainly critics of AD-AS model who nevertheless thought ISLM may have some use. We consider Barro (1994)[6] as an example here. At the time of Barro's writing, AS curve was mainly in classical nature, as can be referred from Barro's writings. As what Barro said in Barro (1994), if AS curve is derived in mostly classical ways, then AS curve's flexbible nature is inconsistent with sticky-price nature of AD side.

But nowadays, there many types of AS curves being taught nowadays with sticky price, wage or imperfect information. Out of them, the most popular one is sticky price one, represented by $P=E[P]+[(1-s) a / s]\left(Y-Y_{n}\right)$, or by an equivalent but more recognizable form $P=s E[P]+(1-s)[P+$ $\left.a\left(Y-Y_{n}\right)\right]$, as seen in page 382 of Mankiw's Macroeconomics textbook. Therefore, Barro's argument does not seem to be relevant today.

Sticky-price AS curve is not without criticism, and one of these criticisms[7] will be referred to as an example. In the sticky-price equation above, given that $E[P]$ remains constant, how AS is derived flows from $\tilde{Y}=Y-Y_{n}$, output gap from natural output level, to $P$ (causality). That is, if demand becomes stronger due to increased output gap, firms who set price flexibly will raise price, resulting in higher price level. However, AD curve's causal nature is from $P$ to $Y$. Therefore, while the resulting AD-AS model is sound algebraically, a such model fails to explain how economy reaches an equilibrium position from a disequilibrium position. When excess supply exists in an economy, creating a disequilibrium, $\mathrm{AD}$ curve tells that price needs to be lowered to generate more demands, boosting output. However, in AS-side if output increases, then given constant expectation, price level increases. Therefore, if an economy ever comes out of an equilibrium, AD-AS becomes unreliable. And it is absurd to say that increasing price level increases output in this AD-AS model. 
For comparison, let us think of ordinary demand-supply model of goods market. In this model, both demand and supply functions are the functions of price $P$. Assume that the market is in excess supply. Then price needs to be lowered to generate more demand. Similarly, lowering of price results in removal of excess supply - and each side gains from such movement due to underlying utility or profit maximization. This is the force that allows equilibrium to be stable, but for sticky-price AD-AS model, a similar stable force cannot be found.

\section{Conclusion}

This paper discussed several issues in connecting loanable funds and ISLM, and how these affect the discussions surrounding fiscal deficit stimulus. While the issues discussed above are mostly related to the models that are only often used in undergraduate economics, nevertheless these issues remain relevant today, as many economists continue to reference these models as useful tools to illustrate their points. I hope more discussions will follow after this short paper.

\section{References}

1: J.M. Keynes, The General Theory of Employment, Interest and Money, Palgrave Macmillan, 1936.

2: N.G. Mankiw, 6th ed., Principles of Macroeconomics, Cengage Learning, 2011.

3: N.G. Mankiw, 7th ed., Macroeconomics, Worth Publishers, 2010. 4: E. Fama, "Bailouts and Stimulus Plans," https://www.dimensional.com/famafrench/essays/bailouts-and-stimulusplans.aspx, 2009.

5: J. Cochrane, "Fiscal Stimulus, Fiscal Inflation, or Fiscal Fallacies?", http://faculty.chicagobooth.edu/john.cochrane/research/papers/fiscal2.htm, 2009 .

6: R. J. Barro, "The Aggregate-Supply/Aggregate-Demand Model,", Eastern Economic Journal vol. 20(1), page 1-6.

7: F. Moseley, "Criticisms of Aggregate Demand and Aggregate Supply and Mankiw's Presentation," Review of Radical Political Economics vol. 42(3), page 308-314. 